\title{
Current Mode Full-Wave Rectifier Based on a Single MZC-CDTA
}

\author{
Neeta Pandey and Rajeshwari Pandey \\ Department of Electronics and Communications Engineering, Delhi Technological University (Formerly Delhi College of Engineering), \\ Bawana Road, Delhi 110042, India \\ Correspondence should be addressed to Neeta Pandey; n66pandey@rediffmail.com
}

Received 30 March 2013; Revised 14 June 2013; Accepted 15 June 2013

Academic Editor: Ali Umit Keskin

Copyright ( 2013 N. Pandey and R. Pandey. This is an open access article distributed under the Creative Commons Attribution License, which permits unrestricted use, distribution, and reproduction in any medium, provided the original work is properly cited.

This paper presents a current mode full-wave rectifier based on single modified Z copy current difference transconductance amplifier (MZC-CDTA) and two switches. The circuit is simple and is suitable for IC implementation. The functionality of the circuit is verified with SPICE simulation using $0.35 \mu \mathrm{m}$ TSMC CMOS technology parameters.

\section{Introduction}

The full-wave rectifiers are used in varied applications [58] such as signal-polarity detectors, averaging circuits, peak value detectors, clipper circuits, and amplitude-modulated signal detectors. Conventionally, full-wave rectifier is implemented using operational amplifiers which are not capable of operating at higher frequencies because of slew rate and fixed gain-bandwidth product limitations [9]. Current mode approach due to its inherent wide bandwidth which is virtually independent of closed loop gain, greater linearity, and large dynamic range [9] has generated lots of interest, and significant research efforts have been directed towards developing new active blocks based on this approach. Among these blocks, CDTA [10-12] has received considerable attention as the external resistors may be implemented by TA block of CDTA, thereby reducing/avoiding external resistors usage in the applications based on CDTA [12] and making these suitable for on-chip implementation. Additionally, due to low input impedance terminals, CDTA is free from parasitic capacitances and hence is appropriate for high frequency operation. This has resulted in development of a wide range of CDTA-based applications [1-4, 11-17].

A variety of FWR circuits using CDTA [1-4] have been reported in the literature. The CDTA-based FWR circuits presented in [1-3] use single CDTA, whereas configuration reported in [4] employs two CDTAs and a multiple output current follower. The structures $[1,2,4]$ use four pn junction diodes, whereas two Schottky diodes are used in [3]. Additionally, auxiliary bias is employed in [1] and a grounded resistor is employed in [4]. In this paper, a new approach for designing a single CDTA-based current mode full-wave rectifier (FWR) configuration is presented. The proposed current mode FWR configuration uses a single CDTA called MZC-CDTA (modified Z copy CDTA) and two MOS switches. The features of the CDTA-based FWR circuits are summarized in Table 1. It may be noted that the proposed FWR uses similar a number of active elements as given in [3]; however, the use of MOS switches makes it more suitable from integration viewpoint. The functionality of the circuit is verified with SPICE simulations using $0.35 \mu \mathrm{m}$ TSMC CMOS technology parameters.

\section{Circuit Description}

The circuit symbol of MZC-CDTA is shown in Figure 1. It is similar to ZC-CDTA except for an extra $z c$ - port. The port relationship of the MZC-CDTA is characterized by the following matrix:

$$
\left[\begin{array}{c}
V_{p} \\
V_{n} \\
I_{z} \\
I_{z c} \\
I_{z c-} \\
I_{x+} \\
I_{x-}
\end{array}\right]=\left[\begin{array}{cccccc}
0 & 0 & 0 & 0 & 0 & 0 \\
0 & 0 & 0 & 0 & 0 & 0 \\
1 & -1 & 0 & 0 & 0 & 0 \\
1 & -1 & 0 & 0 & 0 & 0 \\
1 & -1 & 0 & 0 & 0 & 0 \\
0 & 0 & g_{m} & 0 & 0 & 0 \\
0 & 0 & -g_{m} & 0 & 0 & 0
\end{array}\right]\left[\begin{array}{c}
I_{p} \\
I_{n} \\
V_{z} \\
V_{z c} \\
V_{z c-} \\
V_{x+} \\
V_{x-}
\end{array}\right],
$$


TABLE 1: Summary of available CDTA-based FWR.

\begin{tabular}{lcccc}
\hline Ref. No. & Number of CDTAs & Additional active block & $\begin{array}{c}\text { Number/type of } \\
\text { passive elements }\end{array}$ & $\begin{array}{c}\text { Auxiliary bias } \\
\text { current sources }\end{array}$ \\
\hline$[1]$ & 1 & 4 pn junction diodes & - & Yes \\
{$[2]$} & 1 & 4 pn junction diodes & - & No \\
{$[3]$} & 1 & 2 Schottky diodes & - & No \\
{$[4]$} & 2 & Multiple output current follower, 4 pn junction diodes & 1 grounded resistor & Yes \\
Proposed & 1 & 2 MOS transistors & - & No \\
\hline
\end{tabular}

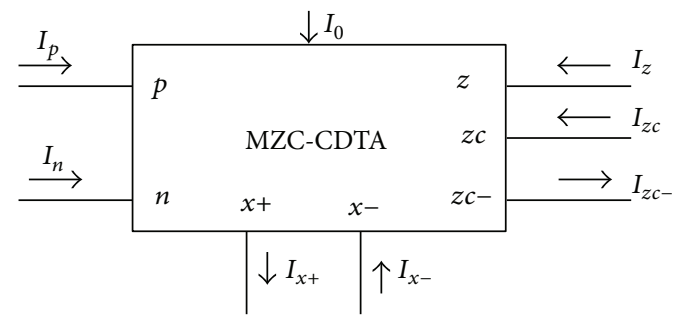

FIgURE 1: Circuit symbol of MZC-CDTA.

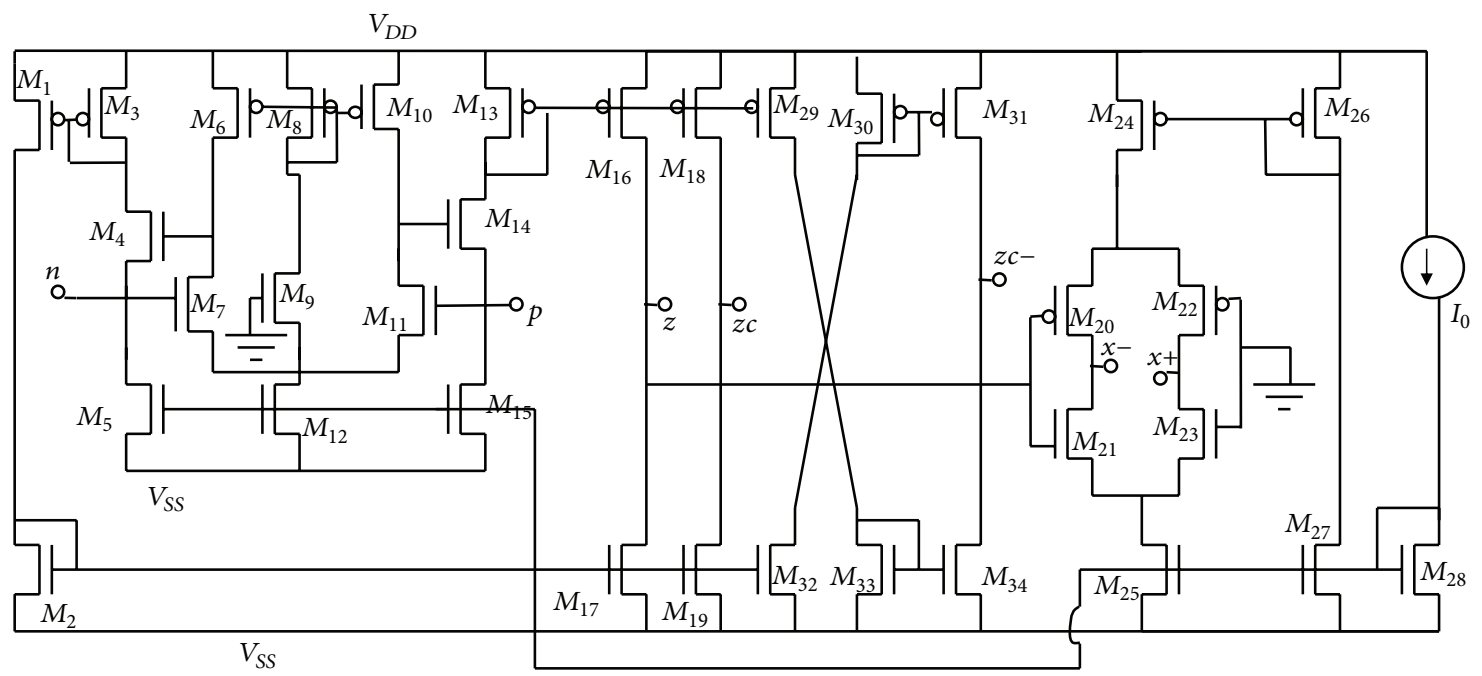

FIGURE 2: MZC-CDTA implementation.

where $g_{m}$ is transconductance of the MZC-CDTA. The CMOS-based internal circuit of MZC-CDTA is depicted in Figure 2 and is based on the CDTA schematic given in [1]. The value of transconductance $\left(g_{m}\right)$ is expressed as

$$
g_{m}=\sqrt{2 \mu C_{o x}\left(\frac{W}{L}\right)_{21,23} I_{0}} \text {, }
$$

which can be adjusted by bias current $I_{0}$ of MZC-CDTA.

The proposed MZC-CDTA-based full-wave rectifier is shown in Figure 3. It uses a single MZC-CDTA and two MOS switches $\left(M_{p 1}\right.$ and $\left.M_{n 1}\right)$ connected at $z c$ and $z c-$ ports, respectively. The $z$ port being open, its voltage would approach to $V_{D D}$ or $V_{S S}$ depending upon the current flowing into $p$ terminal. Further, as $x$ - terminal of the circuit is also

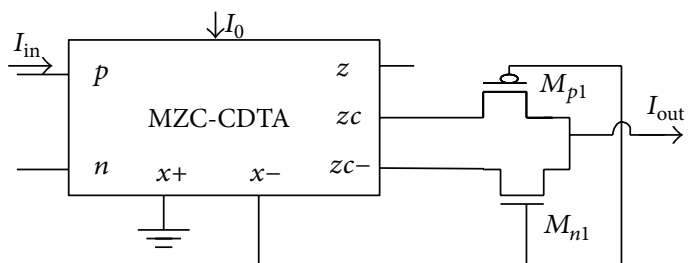

FIGURE 3: Proposed current mode rectifier.

not drawing any current, so for small current inputs, it would be saturating to supply voltage, resulting in

$$
\begin{gathered}
V_{x-}=V_{D D} \quad \text { for } I_{\text {in }} \leq 0 \\
V_{x-}=V_{S S}
\end{gathered}
$$


At any instant, either of the two transistors $M_{p 1}$ and $M_{n 1}$ will be in $\mathrm{ON}$ condition as the current through $z c$ and $z c-$ ports is out of phase. The transistor $M_{p 1}$ will be ON for positive input currents, whereas the negative input current will bring transistor $M_{n 1}$ in ON condition thereby making $I_{\text {out }}$ a unidirectional current.

\section{Nonideal Analysis}

The actual behavior of the circuit may deviate from the ideal one due to error in current transfer from $p$ and $n$ terminals to $z, z c$, and $z c-$ terminals and also current at $x+$ and $x$ - terminals. The current transfer from $p$ and $n$ ports to $z, z c$, and $z c$ - ports may differ from unity value, and these tracking errors are represented by $\alpha_{p}$ and $\alpha_{n}$. The inaccuracy in transconductance transfer from $z$ to $x+$ and $x$ - ports is modeled by $\beta g_{m} V_{z}$. Considering the inaccuracies outlined earlier, the output current $I_{\text {out }}$ becomes a unidirectional current of value $\alpha_{p}\left|I_{\text {in }}\right|$. Depending upon the internal structure and technology used, the tracking errors $\alpha_{p}, \alpha_{n}$, and $\beta$ also have first-order low-pass rolloff which affects the performance at high frequencies.

Apart from the error in the current transfer, there are parasitic impedances at $p$ and $n$ ports (resistances $R_{p}$ and $R_{n}$ ) and shunt output impedances $(R / / C)$ at ports $z, z c, z c-$, $x+$, and $x-$. The input current is applied at $p$ port in the proposed circuit and $n$ port is left open, so resistances at $p$ and $n$ ports do not put restriction in the behavior of the circuit. The impedances at $z, z c, z c-, x+$, and $x$ - ports will have an impact at higher operating frequencies.

\section{Simulation Results}

The functionality of the proposed current mode rectifier is validated using MZC-CDTA schematic of Figure 2. The model parameters of TSMC $0.35 \mu \mathrm{m}$ CMOS process and supply voltages of $V_{D D}=-V_{S S}=1.8 \mathrm{~V}$ are used. The aspect ratios of various transistors are taken from [16], and the bias current of $60 \mu \mathrm{A}$ is used. The circuit of Figure 3 is excited by a $10 \mathrm{KHz}, 20 \mu \mathrm{A}$ sinusoidal current signal. The time domain behaviour of voltage developed at $x$ - port due to input current is shown in Figure 4. For positive half-cycle of the input current, a negative voltage is developed at $x$ - port which in turn makes the transistor $M_{p 1} \mathrm{ON}$, whereas transistor $M_{n 1}$ remains OFF, and thus output current $I_{\text {out }}$ is equal to input current for positive half-cycle. The negative half-cycle of the input current makes $x$ - port voltage positive and turns transistor $M_{n 1} \mathrm{ON}$. The current through transistor $M_{n 1}$ is out of phase with input current, and therefore the output current would be positive. The input and output currents for the proposed circuit under sinusoidal excitation are shown in Figure 5 and conform to the theoretical predictions. The simulated ripple factor curve is plotted in Figure 6 and its value is approximately 0.5 . Figure 7 shows the response of the circuit under sinusoidal excitation. The simulated total power consumption of the circuit is $14 \mathrm{~mW}$.

The DC response of the proposed circuit is also studied and the transfer characteristics are shown in Figure 6. It may

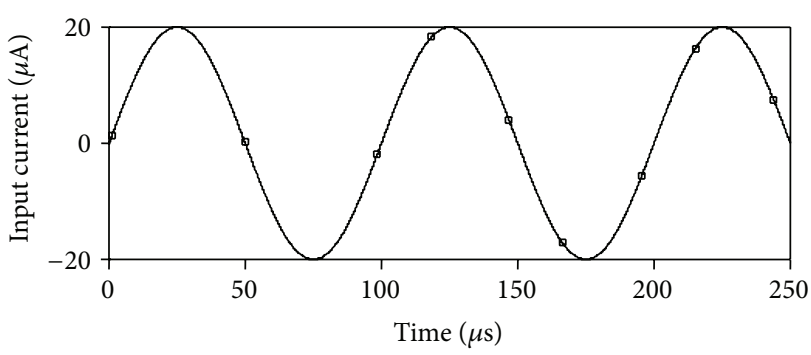

(a)

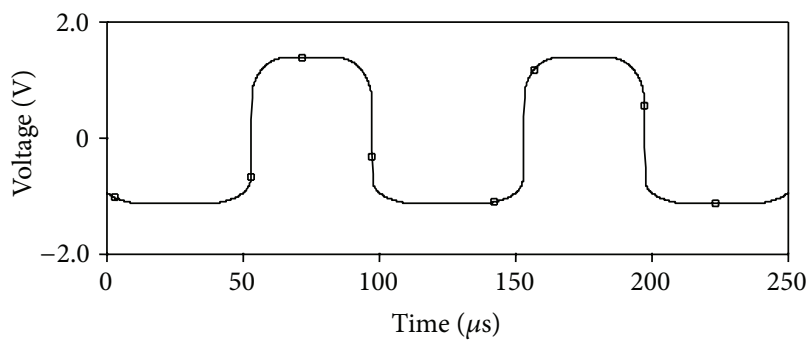

(b)

FIgURE 4: Time domain response of input current and $x$ - port voltage.

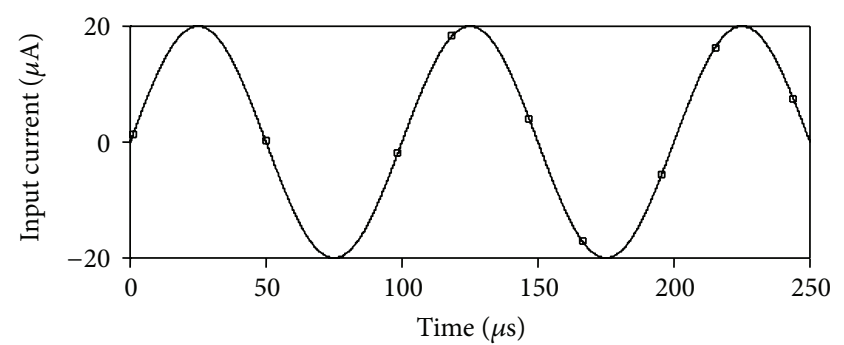

(a)

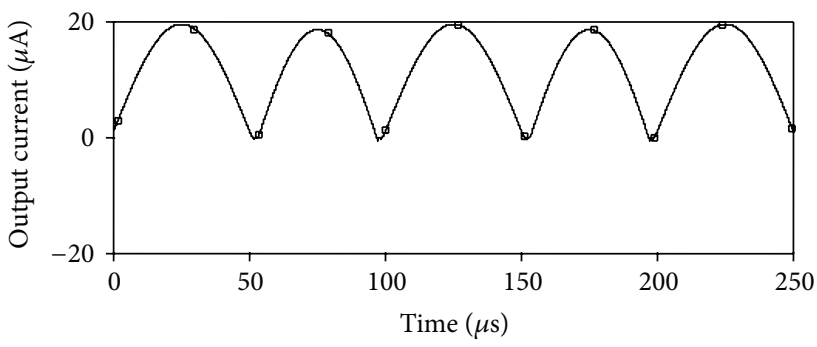

(b)

FIGURE 5: Input and output waveforms for sinusoidal excitation.

be noted that the proposed circuit behavior is linear for input currents ranging between $-300 \mu \mathrm{A}$ and $+300 \mu \mathrm{A}$. The positive and negative slopes of 0.967 and 0.993 , respectively are observed. The deviation of slope from unity value may be attribute to CDTA nonidealities.

The proposed circuit is also tested to judge the level of harmonic distortion at the output of the signal. The \% THD result is shown in Figure 9 which shows that the output distortion is around $22 \%$ for input currents up to $300 \mu \mathrm{A}$. 


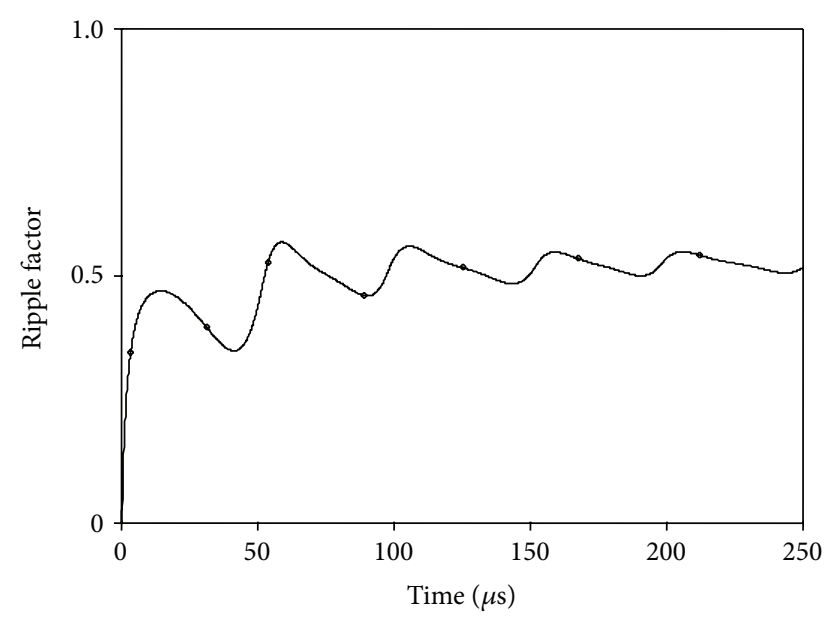

FIGURE 6: Simulated curve for ripple factor.

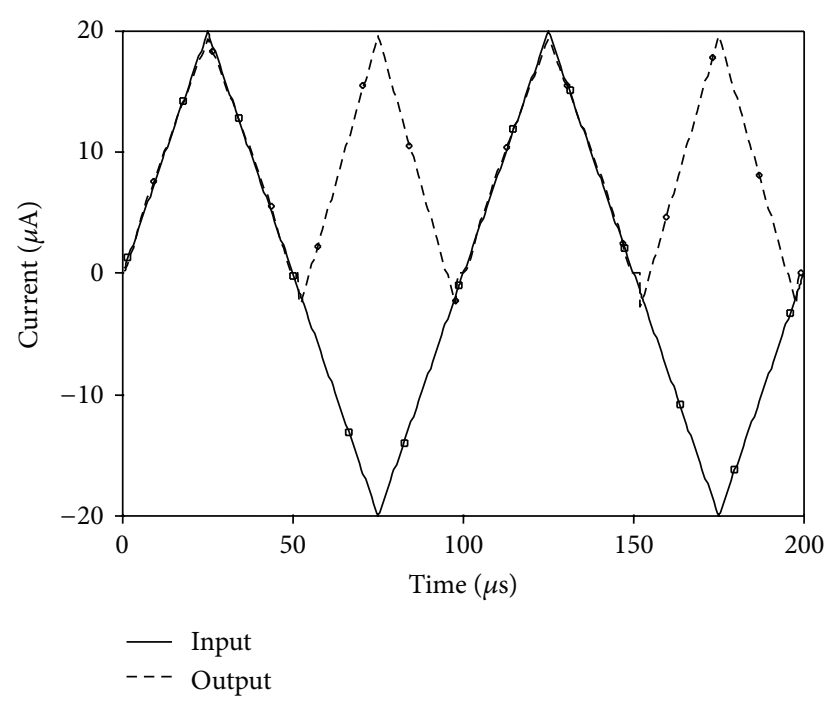

FIGURE 7: Input and output waveforms for triangular excitation.

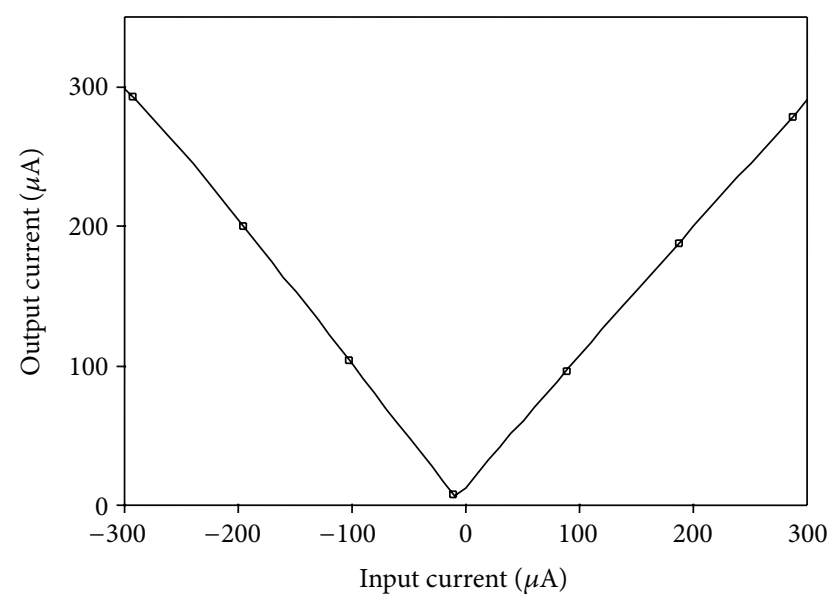

FIGURE 8: DC response of the proposed circuit.

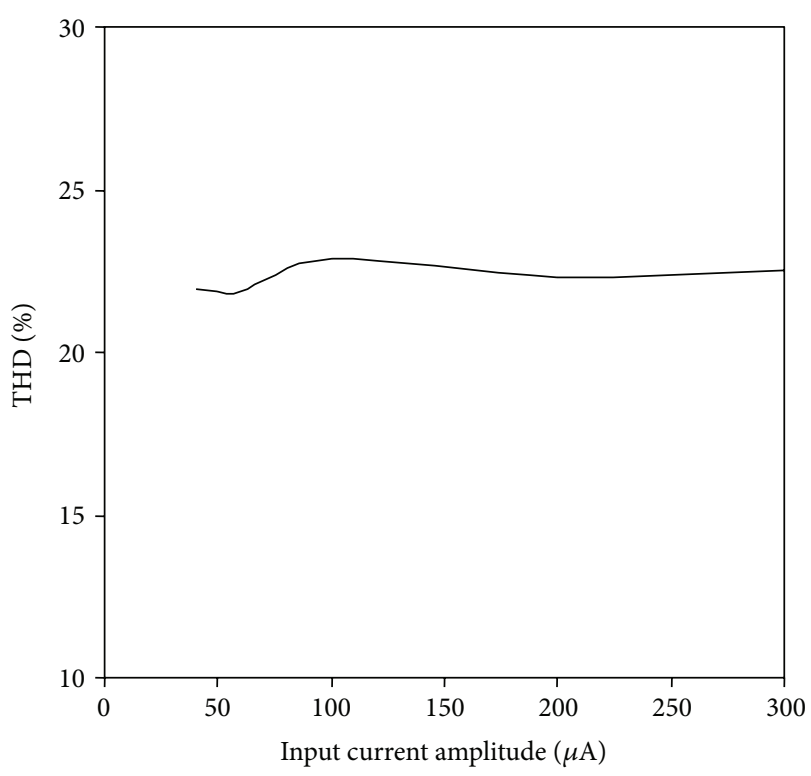

FIgURE 9: Percentage THD versus input bias current.

\section{Conclusion}

A single MZC-CDTA-based current mode full-wave rectifier is presented in this paper. It uses two switches. As the circuit uses only MOS transistors, it is suitable for IC implementation. SPICE simulation results using $0.35 \mu \mathrm{m}$ TSMC CMOS technology parameters are given in support of the theory (see Figure 8).

\section{References}

[1] D. Biolek, E. Hancioglu, and A. Ü. Keskin, "High-performance current differencing transconductance amplifier and its application in precision current-mode rectification," International Journal of Electronics and Communications (AEU), vol. 62, no. 2, pp. 92-96, 2008.

[2] J. Koton, N. Herencsar, K. Vrba, and S. Minaei, "Precision fullwave current-mode rectifier using current differencing transconductance amplifier," in Proceedings of the $3 \mathrm{rd}$ IEEE International Conference on Communication Software and Networks (ICCSN '11), pp. 460-463, Xi'an, China, May 2011.

[3] F. Khateb, J. Vávra, and D. Biolek, "A novel current-mode fullwave rectifier based on one CDTA and two diodes," Radioengineering, vol. 19, no. 3, pp. 437-445, 2010.

[4] W. Tangsrirat, T. Pukkalanun, and W. Surakampontorn, "Synthesis of current differencing transconductance amplifier-based current limiters and its applications," Journal of Circuits, Systems and Computers, vol. 20, no. 2, pp. 185-206, 2011.

[5] S. J. G. Gift, "A high-performance full-wave rectifier circuit," International Journal of Electronics, vol. 87, no. 8, pp. 925-930, 2000 .

[6] S. J. G. Gift and B. Maundy, "Versatile precision full-wave rectifiers for instrumentation and measurements," IEEE Transactions on Instrumentation and Measurement, vol. 56, no. 5, pp. 1703-1710, 2007. 
[7] S. R. Djukic, "Full-wave current conveyor precision rectifier," Serbian Journal of Electrical Engineering, vol. 5, no. 2, pp. 263271, 2008.

[8] K. Hayatleh, S. Porta, and F. J. Lidgey, "Temperature independent current conveyor precision rectifier," Electronics Letters, vol. 30, no. 25, pp. 2091-2093, 1994.

[9] C. Toumazou, F. J. Lidgey, and D. G. Haigh, Analogue IC Design: The Current Mode Approach, chapter 1, Peregrinus, Stevenage, UK, 1990.

[10] D. Biolek, R. Senani, V. Biolkova, and Z. Kolka, "Active elements for analog signal processing: classification, review, and new proposals," Radioengineering, vol. 17, no. 4, pp. 15-32, 2008.

[11] D. Biolek, "CDTA-building block for current-mode analog signal processing," in Proceedings of the ECCTD'03, vol. 3, pp. 397-400, Krakow, Poland, 2003.

[12] A. Ü. Keskin and D. Biolek, "Current mode quadrature oscillator using current differencing transconductance amplifiers (CDTA)," IEE Proceedings: Circuits, Devices and Systems, vol. 153, no. 3, pp. 214-218, 2006.

[13] W. Tangsrirat, W. Tanjaroen, and T. Pukkalanun, "Currentmode multiphase sinusoidal oscillator using CDTA-based allpass sections," International Journal of Electronics and Communications (AEU), vol. 63, no. 7, pp. 616-622, 2009.

[14] A. Lahiri and A. Chowdhury, "A novel first-order current-mode all-pass filter using CDTA," Radioengineering, vol. 18, no. 3, pp. 300-306, 2009.

[15] W. Tangsrirat, T. Pukkalanun, and W. Surakampontorn, "Resistorless realization of current-mode first-order allpass filter using current differencing transconductance amplifiers," Microelectronics Journal, vol. 41, no. 2-3, pp. 178-183, 2010.

[16] A. Lahiri, "Novel voltage/current-mode quadrature oscillator using current differencing transconductance amplifier," Analog Integrated Circuits and Signal Processing, vol. 61, no. 2, pp. 199203, 2009.

[17] D. Prasad, D. R. Bhaskar, and A. K. Singh, "Universal currentmode biquad filter using dual output current differencing transconductance amplifier," International Journal of Electronics and Communications (AEU), vol. 63, no. 6, pp. 497-501, 2009. 

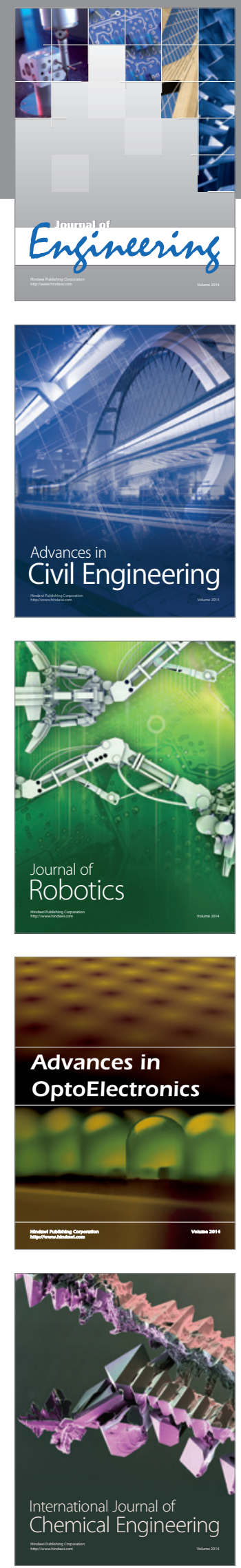

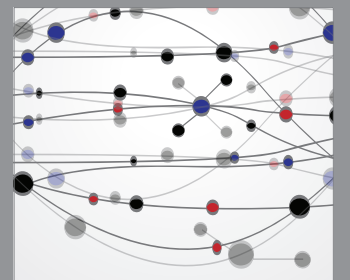

The Scientific World Journal
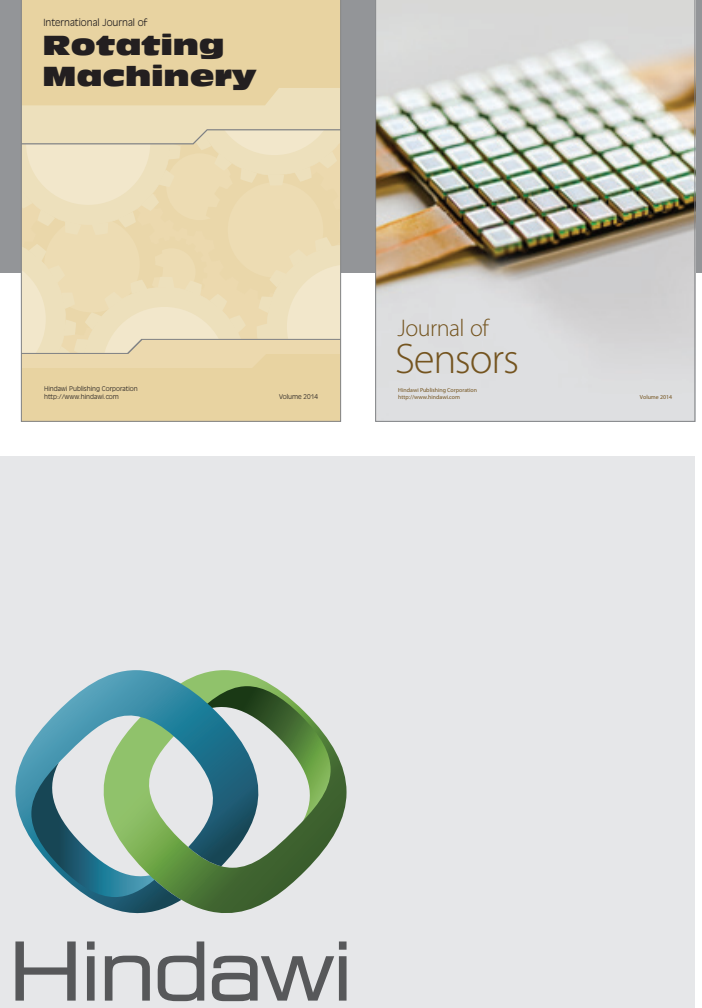

Submit your manuscripts at http://www.hindawi.com
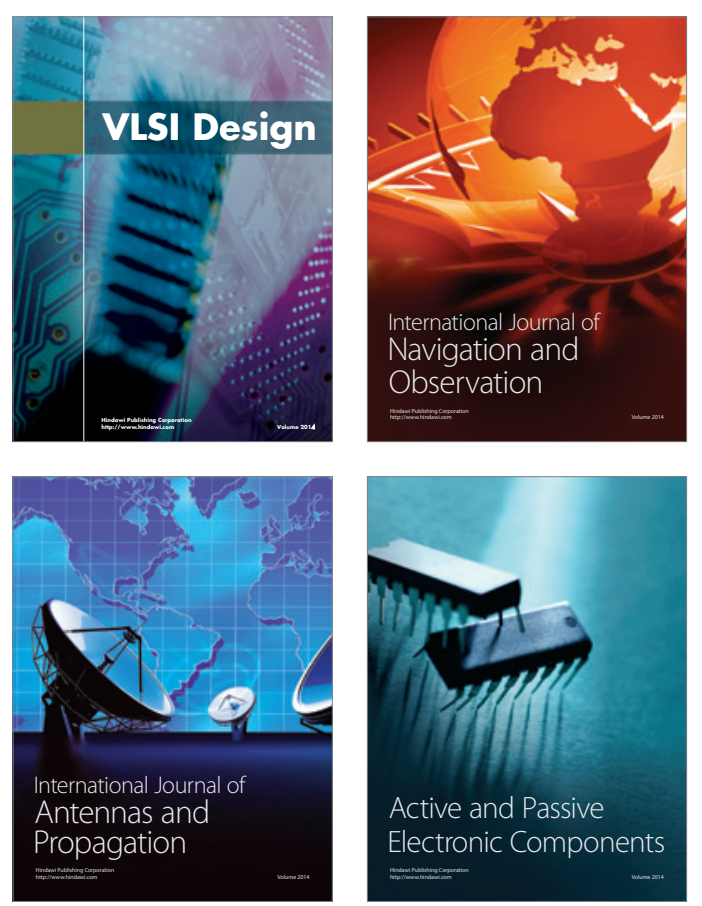
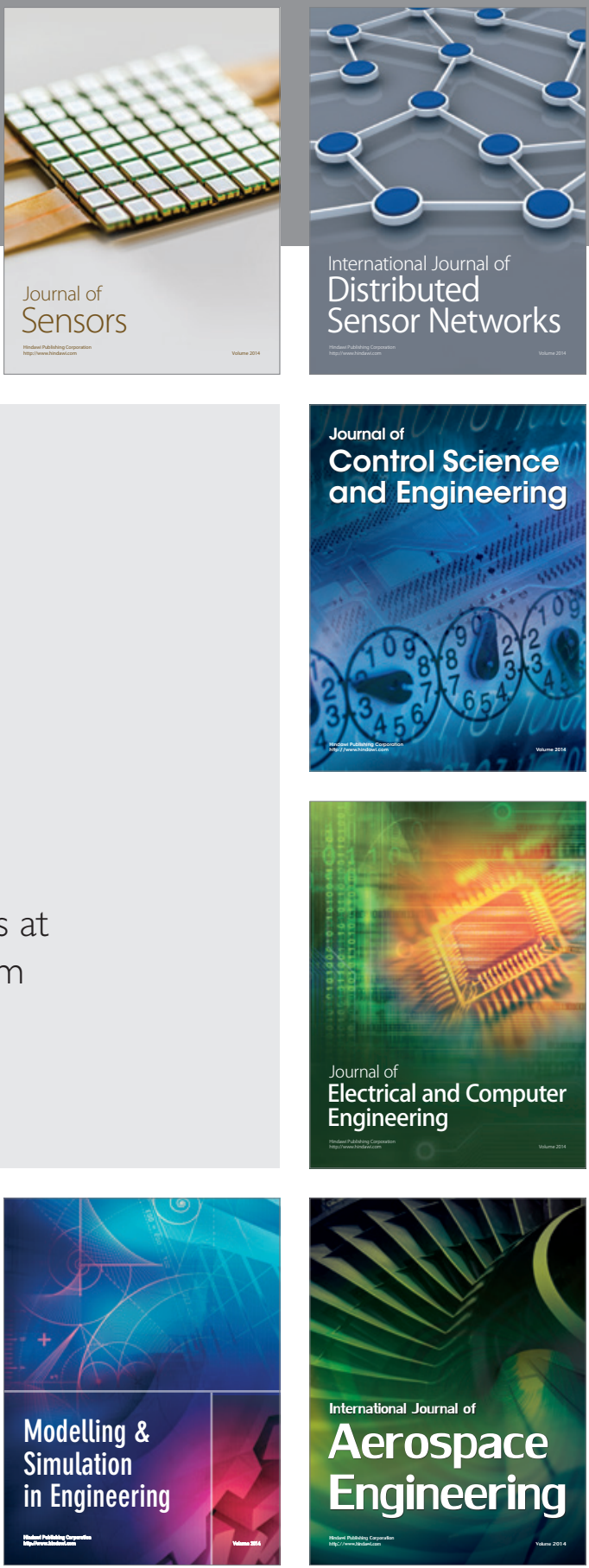

Journal of

Control Science

and Engineering
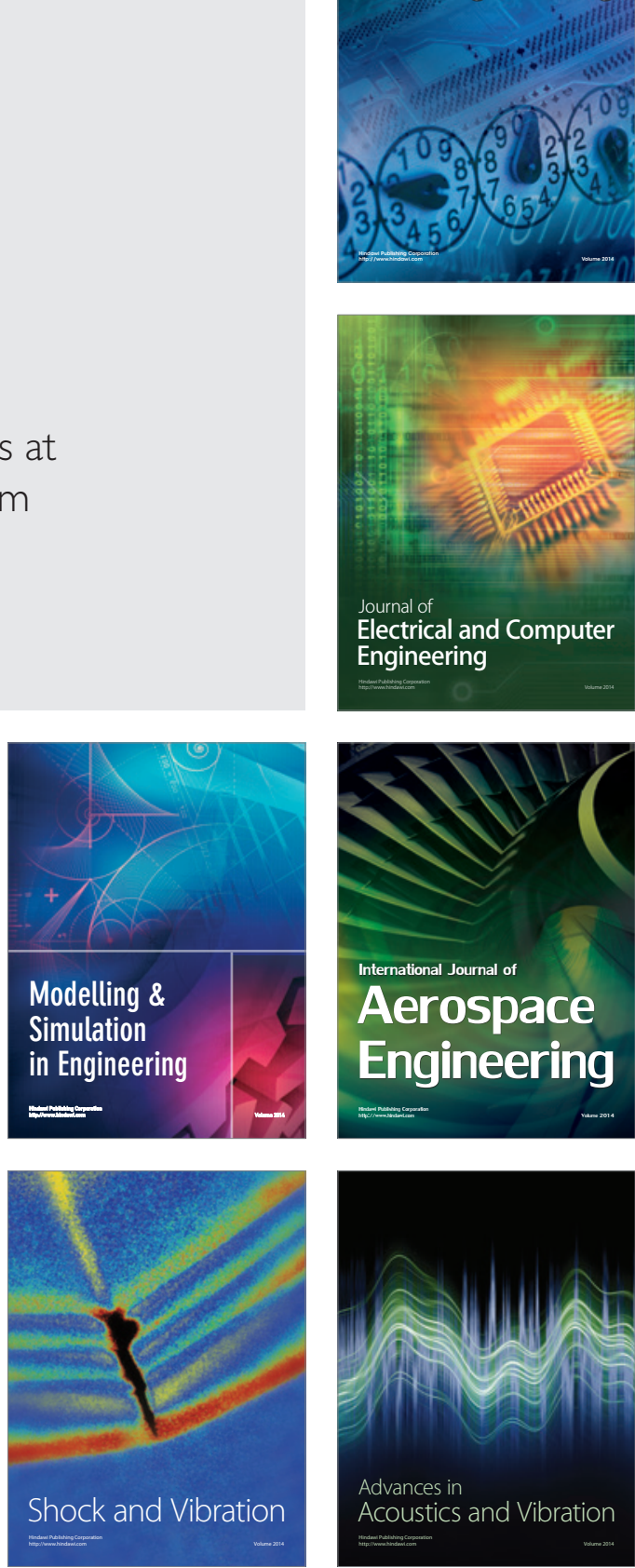